\title{
Analysis the Importance of the Concept of Objective Non-Reality in the Development of Philosophy ${ }^{+}$
}

\author{
En Wang \\ School of Humanities and Social Sciences, Xi'an Jiaotong University, Xi'an 710049, China; \\ welg_glew@163.com; Tel.: +86-029-82665292 \\ + Presented at the IS4SI 2017 Summit DIGITALISATION FOR A SUSTAINABLE SOCIETY, Gothenburg, \\ Sweden, 12-16 June 2017.
}

Published: 8 June 2017

\begin{abstract}
From the origin of ancient Greek philosophy to the philosophy of medieval ages, although it appeared the discussion of "nominalism" and "realism" in medieval times, the exploration of the concept of "objective but non-real" did not get further developed. From the view of the inherent integration of the unity of general rationality on science and philosophy, Professor Wu Kun revived the concept of "objective but non-reality" and creatively developed his "philosophy of information" system. Because the existence of "objective but non-reality" is inherently a kind of "crossover" field in the traditional philosophy, it certainty solve the problems of traditional philosophy from the ontology, which will lead to the breakthrough in the fundamental paradigm in philosophy, and the philosophy begin its fundamental turn.
\end{abstract}

Keywords: objective but non-reality; information; general rationality; paradigm; fundamental turn

\section{Analysis the Concept of "Objective Non-Real" in Philosophy History}

In ancient Greek philosophy, Plato proposed the ideal world as our cognitive object. Only when we grasp the ideal world, can we complete the task of understanding the world. However, Aristotle insisted that the individual things presented in the sensory experience were the first entities, and that all modals (and attributes, commonality, ideas) were contained in individual concrete things and thus they are not the independent entity. In this way, "Porphyry problem" was presented in the history of philosophy, that is, whether the ideal world is the cognitive object in our understanding. In the book "introduction to the Aristotle's book 'Categories'", Porphyry (AD 234-305) said about the species, are they exist independently or rely solely on the idea? If they exist, are they an object or a non-object? After 200 years, Boethius (480-524) translated Porphyry's questions into Latin, which sparked a heated discussion of "Nominalism" and "Realism" in medieval. There were two extremist and moderatism views on this topic in the Middle Ages respectively. The representative of the extreme realism is Anselm, who insisted that the commonality is preceded by and independent of the individual. The representative of the extreme nominalism is Roscelinus (1050-1125). He believed that only individual things are real, and there was no realism at all.

In the development of both of the thoughts, it gradually produced two more moderate and compromise points of view. The representative of the moderate realism was Thomas Aquinas. He explained the relationship between the commonality and the individual in a dialectical view. $\mathrm{He}$ believed that the commonality is before, in, and after the existence of individual things. Abelard represented the thought of moderate nominalism. Abelard explained that "commonality as a universal concept has its objective content and objectivity, not entirely subjective and arbitrary nonsense names, but they themselves is not an independent reality [1]". Therefore, we can conclude that Abelard's thought "conceptualism" implies the concept of "objective and non-real". 


\section{The Contemporary Information Philosophy to Regain and Systematically Developed the Concept of "Objective and Non-Real" in the Existence Field}

From epistemology to linguistics, and phenomenology, modern philosophy has changed a lot. This change actually followed the way of "narrowing the subjective horizon to pursuit and define the main content of philosophy [2]". However, this research paradigm of philosophy made Western philosophy increasingly more one-sided, simplistic, narrow and extreme [2], and the gap between philosophy and science is getting deeper and deeper. In 1960s, under the influence of the philosopher Plantinga, it occurred a new modality analysis in the ontology field. But still, the modality analysis was the traditional view and it didn't jump out and beyond the dichotomy paradigm of the mind and material on the subject and object.

With the development of contemporary science, especially the cluster subjects of information systems in the third scientific revolution, these emerging disciplines provided rich content for the development of philosophy. In the third outbreak of the information revolution, Shannon published his article "A Mathematical Theory of Communication", which became the sign of the birth of information theory. In the same year, Wiener's "Cybernetics" also made an intuitive description on the existence of the information. Wiener pointed out that "information is neither material nor energy". In 1961, the German philosopher Klaus claimed that "except the material and consciousness, there is one third thing, which is objective, but not real" and can be called "information field [3]". However, it is not until the rise of Wu Kun's philosophy of information, professor Wu regained and systematically developed the concept of "objective and not real" in the ontology field.

Further, he clearly gave us the philosophical definition of information: "information is a symbol of indirect existence in the philosophical category, and displays the existence of the mode and state of matter(direct existence) itself [4]. Based on this, professor Wu established the ontology of the binary existence of material and information, the virtual construction epistemology of multi-level information intermediary, the evolution theory of natural and social information and the information value theory of interaction effect. Wu Kun's information philosophy treats the consciousness as the high-level information and puts it into the information which is the indirect existence. Therefore, he achieves the paradigm revolution in ontology level that is "existence = material + information".

The establishment of Wu Kun's philosophy of information breaks the opposite state between objective reality material and subjective non-real mind. Because the existence of "objective and nonreal" itself is a cross-existence category that contains both the objective domain and the non-real field (see Figure 1). The traditional philosophical horizon didn't contain the area of "objective and nonreal". But its own nature contains a bridge of transition and mediation, which provides a transition to solve the binary opposite problem of mind and material. The intermediary has the nature of ontology. Just as professor Wu Kun said, it's "objective information" of objective and indirect existence. Through the intermediary of the information-in-itself rather than find a transcendent existence, we achieve the goal to connect matter and mind well.

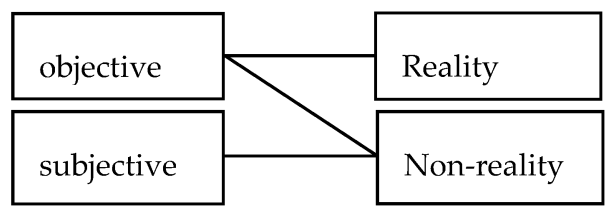

Figure 1. The logic connection of ontology.

\section{The Significance of the Highest Paradigm Revolution Which Is Based on Scientific Development}

Wu Kun's philosophy of information is based on the development of contemporary information science, retrieving the concept of "objective and non-real", which contains the subjective and nonreal mind. As a result, he constructed the concept of "information" in ontology. From the ontological point of view, the definition of information cannot be more essential. From the perspective of 
ontology, the theory answers the problem of "physical and mental sympathetic", which is endlessly debated by traditional philosophy.

The creative discovery of information philosophy is not a chance, but the inevitable trend of the development of science and philosophy. The emerging of the three scientific revolutionsforced the philosophy to make changes to keep up with the scientific discovery and guide the scientific practice. Specifically, the advances in information science have already made the concept of information known to the mass. However, there is no systematic and systematic discussion of the concept of "information", and the information science forces philosophers to make efforts. However, as the modern philosophy went into the mud of subjective consciousness and had difficult to extricate themselves. In Wu Kun's book "philosophy and the turn of philosophy", he says, the "science and philosophy are the activities of human pursuing the universal reason". By combing the history of science and philosophy, professor Wu puts forward the theme of this era "the scientization of philosophy and the philosophization of science".

"Science and philosophy are always embedded together, forming an interaction dynamic circular loop. The inseparability of general rationality and specific sensibility is the ultimate inner unity principle of philosophy and science. The inherent diversity of universal rationality dictates the hierarchy of science or philosophy [2]". Under the influence of Wiener, Shannon, and the Moran and so many scientists of information theory, cybernetics, complexity and Klaus, Lenin and other philosophers, $\mathrm{Wu}$ Kun developed the philosophy of information creatively.

As the philosophical paradigm is hierarchical and has different levels, the renewal of the paradigm in ontology should be the highest paradigm of philosophical revolution. The explanatory power of the traditional philosophy to the world and the understanding of progress of human cognition cannot guide and lead the rapid development of science and technology. This phenomenon is more and more obvious. Even worse, some scientists claimed replacing the philosophy with scientific reason. Although modern philosophy has turned its direction many times, just as professor $\mathrm{Wu}$ Kun analyzes, "the turn of epistemology emphasizes the subjective knowing form; the practice philosophy emphasizes the subjective practice activities; philosophy of language emphasized the formal logic of the symbols in the ways of thinking; the phenomenology emphasized the intentionality of consciousness [2]". However, these perspective transformations are just the shift of the research issue. The mode of ontology and epistemology is still traditional, which is challenged by the latest discovery of quantum mechanics. According with the traditional scientific cognitive model, the so-called scientific objective conclusion, however, the scientific experiments of quantum mechanics have displayed the inevitable effect when scientists involve the experiments, which shocked the traditional binary of subject and object cognitive model. In this case, according to Kuhn's "paradigm revolution" theory, when the conventional philosophical paradigm cannot effectively explain the exception and anomaly, to some degree, this crisis will inevitably erupt and the philosophical paradigm revolution will occur. The highest paradigm revolution is the breakthrough and change in ontology. In this sense, Wu Kun's information philosophy is the first time to achieve the fundamental paradigm revolution of human philosophy. Philosophy regains its vitality from the isolated state, guiding human's ways of thinking and scientific practice, restoring the original lofty status and dignity of philosophy which it deserves.

Acknowledgments: This paper is supported by National Social Science Fund major project "epistemological research of contemporary philosophy based on information technology" (15ZDB019).

Conflicts of Interest: The authors declare no conflict of interest. 


\section{References}

1. Deng, X.; Zhao, L. History of Western Philosophy (Revised Edition); Higher Education Press: Beijing, China, 2014; p. 100.

2. Kun, W. Philosophy and the Turn of Philosophy; People's Publishing House: Beijing, China, 2014; pp. 1, 5, 226.

3. (East German) Klaus, G. From the Philosophy to See Control Theory; Liang, Z., Translator; China Social Science Press: Beijing, China, 1981; p. 61.

4. Kun, W. Philosophy of Information-Theory, System and Method; Commercial Press: Beijing, China, $2005 ;$ p. 46.

(C) 2017 by the authors. Licensee MDPI, Basel, Switzerland. This article is an open access article distributed under the terms and conditions of the Creative Commons Attribution (CC BY) license (http://creativecommons.org/licenses/by/4.0/). 